\title{
Resumo de Artigo
}

\section{Quando a apendicite é suspeitada em crian-} ças.

Sivit CJ, Siegel MJ, Applegate KE, Newman KD. When appendicitis is suspected in children. RadioGraphics 2001;21:247-62.

Apendicite aguda é a causa mais comum de abdome agudo na infância, e o diagnóstico tardio pode trazer sérias conseqüências, como perfuração, formação de abscesso, peritonite, sepse, obstrução intestinal e morte.

A radiografia abdominal convencional mostra-se relativamente pouco sensível e inespecífica para elucidar o diagnóstico, tendo valor quando há suspeita de obstrução intestinal ou perfuração do apêndice.

As vantagens do corte tomográfico incluem o diagnóstico precoce ou a visualização de outra condição que mimetize apendicite, reduzindo as laparotomias brancas e as taxas de perfuração e diminuindo os custos.

\section{Ultra-sonografia (US) com compressão dosada}

Sensibilidade de $85 \%$ e especificidade de $92 \%$ foram relatadas em uma meta-análise de estudos em adultos e crianças, entre 1986 e 1994.

Os exames são realizados com alta resolução e transdutor linear. Faz-se compressão dosada na parede anterior do abdome, resultando no deslocamento e compressão do intestino, com a visualização da veia ilíaca e do músculo psoas, com o apêndice anterior a essas estruturas. Primeiramente, deve-se identificar o cóIon ascendente (aperistáltico e com gás e líquido), seguindo para íleo terminal (com peristalse ativa) e 1-2 cm abaixo para o apêndice. A técnica adequada pode ser realizada em $95 \%$ dos pacientes, sendo limitada quando há presença de dor intensa ou de obesidade.
O apêndice não perfurado aparece preenchido por líquido, não comprimido e como estrutura tubular em fundo cego. 0 diâmetro máximo é de $6 \mathrm{~mm}$; a mucosa é representada por uma linha ecogênica interna. Tendo líquido no lúmen apendicular, uma imagem em alvo é caracterizada por mucosa e submucosa ecogênicas no plano axial. Pode ainda ocorrer o aparecimento de apendicolito, como um ponto ecogênico com sombra acústica, líquido pericecal ou periapendicular, aumento da ecogenicidade periapendicular representando infiltração, e nódulos linfáticos aumentados. 0 único sinal específico para apendicite aguda é o apêndice aumentado, não comprimido e medindo mais que $6 \mathrm{~mm}$.

A perfuração ocorre em $23 \%$ a $73 \%$ das crianças. Os achados ultra-sonográficos incluem camada submucosa menos ecogênica, presença de líquido periapendicular ou pélvico, ou abscesso.

O uso da US com Doppler colorido auxilia no diagnóstico; embora não aumente a sensibilidade, pode aumentar a confiança do examinador. Em apendicite não perfurada mostra hiperemia de parede devido a hiperperfusão inflamatória. $\mathrm{O}$ fluxo colorido pode estar ausente no início do quadro ou limitado à ponta do apêndice. Na perfuração observa-se hiperemia no tecido periapendicular ou dentro de um abscesso bem definido.

\section{Tomografia computadorizada (TC) helicoidal}

Tem-se mostrado de alta sensibilidade e especificidade no diagnóstico de apendicite aguda, com sensibilidade de $87 \%$ a $100 \%$ e especificidade de $89 \%$ a $98 \%$, tendo ainda, como vantagens sobre a US, sensibilidade superior de contraste, ser pouco examinador dependente, e capacidade de visualização do ar, tecidos, gorduras e osso. A TC também é mais útil na avaliação das complicações, como fleimão e abscesso, podendo ainda identificar coleções líquidas e abscesso interalças.

As características tomográficas de apendicite aguda incluem um apêndice maior que 7 $\mathrm{mm}$, parede espessada e apendicolito, ápice do ceco circunferencial ou focal espessado, gordura pericecal, parede intestinal adjacente espessada, líquido peritoneal livre, linfonodopatia mesentérica, fleimão intraperitoneal, ou abscesso, sendo específicos para apendicite o aumento do apêndice e a alteração no ápice cecal. A identificação do apendicolito não deve ser confundida com retenção de bário.

\section{Douglas Teixeira Freire}

Monitor de Radiologia da Faculdade de Medicina de Teresópolis (FMT) - Fundação Educacional Serra dos Órgãos (FESO)

\section{Comentário sobre o artigo}

Neste artigo é revisado o papel da imagem, a eficácia do diagnóstico ultra-sonográfico sob compressão dosada, o uso da TC para o diagnóstico, e as características das imagens na US e na TC.

Dessa forma, foi observado que a US sob compressão dosada e a TC helicoidal mostraram-se úteis na suspeita de apendicite aguda na criança, tendo a US, como principais vantagens, o baixo custo, a ausência de radiação ionizante e o acesso à vascularização apendicular pelo Doppler, além de ajudar no diagnóstico diferencial de doenças ginecológicas, enquanto a TC possui maior acurácia, não é tão dependente do examinador, revela a extensão da doença e possui boa utilidade em pacientes obesos, ao contrário da US.

\section{Marcelo Souto Nacif}

Professor de Radiologia da FMT-FESO 